\title{
Reforms in Public Bus Services in Israel
}

\author{
Yoram $\operatorname{Ida}^{1,2} \&$ Gal Talit ${ }^{1,2}$ \\ ${ }^{1}$ Department of Public Policy, Tel-Aviv University, Tel-Aviv, Israel \\ ${ }^{2}$ Hazan Center for Social Justice and Democracy, the Van Leer Jerusalem Institute, Jerusalem, Israel \\ Correspondence: Yoram Ida, Department of Public Policy, Tel-Aviv University, P.O.B. 69040, Tel Aviv 6997801, Israel
}

Received: August 10, 2015

Accepted: August 21, 2015

Available online: September 6, 2015

doi:10.11114/ijsss.v3i6.1071

URL: http://dx.doi.org/10.11114/ijsss.v3i6.1071

\begin{abstract}
This research presents the main results of tendering bus services in Israel from 2000 to 2014. The article discusses the impact of different tender characteristics on reform results in general, and in Israel, in particular. The article also examines the reform's impact on the quality of government regulation of public bus services. Since many countries are facing issues related to bus service regulation, the issues discussed in this article, combined with the Israeli experience in this field, are likely to be relevant to other countries in which similar reforms have been implemented.
\end{abstract}

Keywords: public transportation, bus services, competitive tendering, regulation, supervision and control

\section{Introduction}

Many countries have implemented reform in public bus services. The need for such reform arose from inefficiency in this market, manifest in rising costs of supplying the services (Hensher \& Houghton, 2004), alongside a decline over time in the number of users, mainly due to the increased shift to using private vehicles. In time, policy makers recognized the need for market-oriented changes in order to reduce costs and public expenditure, and to encourage more consumers to use public transportation, and especially buses, which are the main transportation vehicles in most countries.

The main concern when implementing reform is that full removal of regulation may lead to the limitation of routes to those with high profit potential, leaving unprofitable routes, which public transportation authorities consider essential, without suitable services. For this reason, most western European countries, including Israel, have preferred a system of competitive tendering. In this framework, the transportation authority defines clusters of bus routes for competition. The state grants the winning bidder exclusive rights to supply the service for a limited time period; the operator, in return, is obliged to meet the terms and standards specified in the contract. The main benefit of this arrangement for the state is that it retains some control over the supply of services throughout the contract period. The effectiveness of the regulation is measured by the regulator's ability to ensure the operator fulfills its contractual commitments, that is, provides at least the level and quality of services determined in the contract (Muren, 2000).

A comparative study of the outcome of reforms in different countries indicated that competitive tendering has usually resulted in considerable savings in costs and in the level of subsidies required in order to supply a given level of service, arising mainly from a substantial reduction in the wages of the bus drivers (Walters, 2010). With respect to the level and quality of the services, the fares, and the number of passengers, the results varied among locations (Hensher \& Wallis, 2005).

This suggests that in some places, there was a preference for investing the resources saved in improving the services, and in others, the preference was to redirect the resources saved to finance other activities. For example, in areas of Britain outside of London (White, 1997), the decision makers preferred to use the resources saved mainly in order to reduce public expenditure and subsidies. Scandinavian countries, in comparison, preferred to use the resources saved mainly to improve the service and increase the number of passengers (Hidson \& Muller, 2003). The different objectives led to different tender characteristics, which served as the tools available to authorities and regulators in order to achieve their objectives.

In Israel, two cooperatives supplied $96 \%$ of the public bus transportation for many years. In 2000, public transportation service reform was introduced. Its main objectives were to improve the standard of service and increase the number of passengers. Increasing the economic efficiency of the public bus transportation was intended to provide the resources to 
achieve these objectives. In 2012, the new operators accounted for $34 \%$ of the activity in the industry (in terms of $\mathrm{km} /$ vehicle), and by 2017 , their portion is expected to increase to $45 \%$.

The current research presents the main results of competitive tendering in Israel, and discusses the impact of different tender characteristics on the quality of regulation in the public transportation industry, in general, and in Israel, in particular.

\section{The results of the bus reform in Israel}

Similar to other countries, the bus reform in Israel led to several changes. First, the average cost per vehicle kilometer decreased by $37 \%$ to $50 \%$. The main savings in cost was the result of a decline in wages, mainly of the drivers (Ida, 2009). Second, changes were made in the level of service, bus fares, and number of passengers. As shown in Table 1, in most of the clusters included in the tenders, the level of service and number of passengers increased, and in some there was also a decrease in bus fares. Additional measures reflected improvement in the quality of the service supplied to the passengers, as well. Third, frequent changes were made in the characteristics of the tenders, such as the division of authority, contract type, contract period, competition criteria, and the supervision and control system.

Table 1. Change in level of service, fares, and number of passengers in Israel, 2000-2010 (\%)

\begin{tabular}{|c|c|c|c|c|}
\hline Cluster of lines & $\begin{array}{c}\text { Type of service } \\
\text { (urban, intercity, } \\
\text { mixed) }\end{array}$ & $\begin{array}{c}\text { \% change in } \\
\text { level of } \\
\text { service } \\
(2010)\end{array}$ & $\begin{array}{c}\text { \% change in } \\
\text { number of } \\
\text { passengers } \\
(2010)\end{array}$ & $\begin{array}{l}\% \text { change in } \\
\text { tariffs }\end{array}$ \\
\hline Nahariya - Zefat & mixed & 52 & 45 & -24 \\
\hline Hadera - Netanya & intercity & 86 & 105 & -19 \\
\hline Ramla - Matityahu & mixed & 118 & 99 & -20 \\
\hline Beer Sheva - Tel Aviv & intercity & 104 & 67 & -45 \\
\hline Tiberias & urban & 126 & 45 & -52 \\
\hline Ashdod - Tel Aviv & intercity & 62 & 86 & -56 \\
\hline Bikat Ono & urban & -21 & 3 & -10 \\
\hline Elad & mixed & 32 & 63 & 20 \\
\hline Beer Sheva & urban & 17 & 17 & 5 \\
\hline North Negev & mixed & 35 & 34 & 24.5 \\
\hline Emeq Yizrael & mixed & 33 & 72 & 25 \\
\hline Modiin & mixed & -18 & 21 & 0 \\
\hline Petah Tikva & urban & -20 & -8 & 2.5 \\
\hline Betar Illit & mixed & 18 & 225 & 0 \\
\hline Netanya - Tel Aviv & intercity & 1 & 62 & 26 \\
\hline Jerusalem Corridor & mixed & 3 & 63 & 21 \\
\hline Rahat & mixed & -7 & -40 & $30-40$ \\
\hline Ashdod & urban & -3 & 28 & 4 \\
\hline Shomron & mixed & 0 & -2 & 0 \\
\hline Lod - Tel Aviv & mixed & 1 & -25 & 20 \\
\hline Sharon & mixed & NA & NA & 0 \\
\hline Yoqneam - Tivon & mixed & 0 & NA & 1 \\
\hline Bnei Brak - Jerusalem & intercity & NA & NA & 0 \\
\hline
\end{tabular}

Source: Israel's Public Transportation Authority, 2012.

\section{Discussion}

The outcomes of the competitive tendering in Israel indicate success in terms of most of the variables examined: savings of cost, improvement of service level and quality, and increasing the number of passengers. However, the frequent changes introduced may reflect lack of fit between the tender characteristics and its defined purposes and/or problems with government regulation. An in-depth examination of the reform indicated the following changes in characteristics. 


\subsection{Division of regulatory authority}

Research has shown that integration and management of several modes of public transportation on a regional or metropolitan level enable greater efficiency and more effective control (Hensher Houghton, 2004). In addition, some involvement of the operators on the tactical level (setting the routes, fares, frequencies) has been associated with improved service and an increased number of passengers (Hensher \& Stanley, 2010).

In Israel, the authorities are concentrated at the national level (the ministry of transportation), which may impair the ability to regulate the process. In addition, the nearly total absence of operator involvement on the tactical level prevents the transportation authority from utilizing the knowledge of the operators, who are closer to the endpoint of customer contact.

\subsection{Type of contract and division of risk}

The two most common types of contract are gross-cost and net-cost. In a gross-cost contract, the operator bears only "production risk," that is, the risk involved in the expense of producing a set output, regardless of the number of passengers. In a net-cost contract, the operator receives the income from selling services and also bears the "revenue risk," that is, the risk regarding the amount of revenue obtained by selling the public transportation services.

The main advantage of gross-cost contracts is the relatively low cost to the public transportation authority, greater ability to coordinate among the operators, and greater control over the operators. The main advantage of net-cost contracts is the inherent incentive for operators to supply a higher standard of service (Muren, 2000). Therefore, there is a tendency to consider this as the most suitable type of contract for achieving improved service and increased number of passengers.

Until 2010, all the tenders in Israel were net-cost type. A comprehensive study found that the cost-and-demand structure in Israel did not motivate the operators to provide a high level of service. Thus, gross-cost tenders seem more feasible (Ida, 2009), and in 2010, the transportation authority began using them instead. In order to motivate the operators to supply a high standard of service, these tenders also include incentives for increasing the number of passengers (Amaral, Saussier, \& Yvrande-Billon, 2009).

\subsection{Contract period}

The length of the contract period is an important component in assuring a good standard of service. If the period is too long, it may fail to create an effective threat to the operator, and not sufficiently motivate the provision of good service. A low frequency of tenders also reduces the possibility of adjusting the services to changes in technology or demand. A relatively long contract period also has advantages: greater feasibility for the operator to invest in capital, workforce, and equipment; greater possibility of finding sources of financing; learning in the course of providing service; and better job security, particularly for drivers.

When the reform began, the tenders in Israel referred to a six-year contract period, which was extended later to eight years. In the last four tenders, the contract period was $6+3+3$ years (6 years and two possible extensions of 3 years each). This last change may, theoretically, resolve the problem of setting a too-long contract period from the start and thus establishing the operator as a regional monopoly. However, if extension of the contract period is based on operator performance, it doesn't solve the problem of the operator's uncertainty regarding the contract period. Otherwise, it may worsen the problem of creating a regional monopoly, since the operator may consider it an automatic extension mechanism.

\subsection{Variables of competition}

The choice of operator is usually a two-stage process. The first stage is the initial screening, intended to prevent the entry of operators that fail to meet the minimum requirements of financial solidity and previous experience. However, creating impenetrable barriers is liable to impair competition. In Israel, there have recently been discussions of raising the screening criteria in order to prevent the entry of small companies. On the one hand, the regulator's inclination to prefer the relative financial strength and economies of scale of large operators is understandable. On the other hand, it may hinder market competition and increase the risk of collusion among operators. In the medium to long run, this situation might also lead to replacement of the public monopoly with regional monopolies from the private market, at the expense of efficiency and service standards.

The second stage is the tender, including determination of the criteria for winning. These criteria must reflect the aims and goals defined by the regulator and the relative importance of each of them. For example, giving heavy weight to the financial aspect of the offers reflects a focus on cutting the costs and subsidies required and less attention to the improvement of service.

Examination of the criteria for selecting the operators in Israel over time reveals many changes, for several reasons, 
particularly (a) a shift in emphasis from reducing fares and increasing the scope of service to saving on subsidies; (b) an effort to prevent dumping bids and renegotiation after winning the tender; and (c) an attempt to link the level of subsidy to the number of passengers.

In 2006, two regulatory measures were adopted for the purpose of quality assurance and service continuity. One was consideration of the operational control score and past experience of the operator; the other was inclusion of the drivers' wages and the operator's plans for investment in their training. In the past four tenders (since 2010), which were gross-cost tenders, the criteria have focused on both cost savings and on the service proposed, with relatively greater weight ascribed to operational programs that included a definition of the standard of service.

\subsection{System of operational supervision and control}

Once the winning bidder begins operating, the operational supervision and control system is the main instrument for maintaining the required standard of services. In some places, control is based on consumer satisfaction surveys (Hensher \& Prioni, 2002), and operators are rewarded for fulfilling the targets set in the tender. In other places, the control serves as the basis for decisions about renewing the contract and for considering proposals from operators in new tenders.

In Israel, inclusion of the operators' standard-of-service score as one of the criteria for awarding the tender, and increasing its relative weight from $5 \%$ to $17 \%$ significantly increased the importance of the regulatory instrument. However, the standard of service index does not include passenger preference surveys, which could provide essential information on the importance they ascribe to the different elements of the index (Hensher \& Prioni, 2002). Another disadvantage of this index is the relatively low number of bus trips measured for each operator (about $0.4 \%$ of all rides), which may not be sufficient to deter operators from deviating from the required standard.

\section{Summary}

Competitive tendering may be an effective means for achieving the targets of saving costs of providing and improving public bus service. The difference in the level of service provided in different places in the world stems from different priorities regarding the use of the resources saved, and different tender characteristics.

In Israel, the characteristics of the tenders have been changed frequently over the years, with the aim of improving the standard of service and increasing the number of passengers on buses. In order to attain these goals, the regulator adopted several changes: (a) a shift to gross-cost tenders with incentives for operators; (b) focusing the competition on improved service and increased number of passengers; and (c) inclusion of an operational control index as a significant criterion for selecting the operator.

In Israel there are also several characteristics that hinder achievement of these goals: (a) the division of authority between the regulator and the operators is not optimal. The distance of the regulator from the end point of the service and the exclusion of operators from involvement at the tactic level hinder the achievement of improved service and increased numbers of passengers; (b) diminishing the number of companies in the market may reduce competition; (c) extension of the contract period may reduce the level of competition in the medium to long run. It is too early to assess the impact of a short contract period with two possible extensions, subject to the conduct of the operators; (d) evaluating just a small portion of their rides may not deter operators from deviating from requirements; and (e) the operational control index does not include consumer preference surveys, and may not correctly reflect the value of the service standards to the consumer.

Adaptation of the characteristics described in the research to the changing conditions may improve the ability to achieve the goals by means of competitive tendering and benefit those who use bus services.

\section{Acknowledgements}

The authors would like to thank the Van Leer Jerusalem Institute - Hazan Center for Social Justice and Democracy for their financial support.

\section{References}

Amaral, M., Saussier, S., \& Yvrande-Billon, A. (2009). Auction procedures and competition in public services: The case of urban public transport in France and London. Utilities Policy, 17(2), 166-175. http://doi:10.1016/j.jup.2008.07.006

Hensher, D. A., \& Houghton, E. (2004). Performance based contracts [working paper ITS-WP-04-03]. Sydney, New South Wales, Australia: Institute of Transport Studies, University of Sydney. Retrieved August 31, 2015, from http://ws.econ.usyd.edu.au/itls/wp-archive/itls_wp_04-03.pdf

Hensher, D. A., \& Prioni, P. (2002). A service quality index for area-wide contract performance assessment. Journal of 
Transport Economics and Policy, 36(1), 93-113.

Hensher, D. A., \& Stanley, J. (2010). Contracting regimes for bus services: What have we learnt after 20 years? Research in Transportation Economics, 29, 140-144. http://dx.doi.org/10.1016/j.retrec.2010.07.018

Hensher, D. A., \& Wallis, I. P. (2005). Competitive tendering as a contracting mechanism for subsidizing transport - the bus experience. Journal of Transport Economics and Policy, 39(3), 295-321.

Hidson, M., \& Muller, M. (2003). Better public transport for Europe through competitive tendering. Germany: ICLEI Local Governments for Sustainability.

Ida, Y. (2009). Efficient competitive tendering for public transportation Services (Unpublished doctoral dissertation). Tel Aviv University, Tel Aviv, Israel (Hebrew).

Muren, A. (2000). Quality assurance in competitively tendered contracts. Journal of Transport Economics and Policy, 34(1), 99-112.

Public Transportation Administration (2012). Reports (Hebrew).

Walters, J. (2010). Is the bus transport contracting system in South Africa leading to trusting relationships between contracted parties? An analysis of funding issues and the impact on relations between government and operators. Research in Transportation Economics, 29(1), 362-370. http://doi:10.1016/j.retrec.2010.07.046

White, P. (1997). What conclusions can be drawn about bus deregulation in Britain? Transport Reviews, 17(1), 1-16.

\section{(c) $\mathrm{BY}$}

This work is licensed under a Creative Commons Attribution 3.0 License. 